\title{
Animal Health Challenges and Veterinary Aspects of Organic Livestock Farming Identified Through a 3 Year EU Network Project
}

\author{
Mette Vaarst ${ }^{*}, 1$, Susanne Padel $^{2}$, David Younie ${ }^{3}$, Malla Hovi ${ }^{4}$, Albert Sundrum ${ }^{5}$ and \\ Caroline Rymer ${ }^{1}$
}

\author{
${ }^{I}$ Department of Animal Health, Welfare and Nutrition, Faculty of Agricultural Sciences; University of Aarhus, P.O. Box \\ 50, DK- 8830 Tjele, Denmark \\ ${ }^{2}$ Institute of Rural Sciences, Aberystwyth University, Llanbardarn Campus, Aberystwyth, SY233AL, UK \\ ${ }^{3}$ Scottish Agricultural College, Craibstone Estate, AB219YA, Aberdeen \\ ${ }^{4}$ Animal Health Divisional Office, Coley Park, Reading, RG1 6LY, UK \\ ${ }^{5}$ University of Kassel, Nordbahnhofstr. 1a, D-37213 Witzenhausen, Germany
}

\begin{abstract}
From 2003-2006, an EU network project 'Sustaining Animal Health and Food Safety in Organic Farming' (SAFO), was carried out with 26 partners from 20 EU-countries and 4 related partners from 4 candidate or new member states. The focus was the integration of animal health and welfare issues in organic farming with food safety aspects. Four very consistent conclusions became apparent: 1) The climatic, physical and socio-economic conditions vary considerably throughout Europe, leading to different livestock farming systems. This limits the possibility for technology transfer between regions, and creates several challenges for a harmonised regulation, 2) Implementing organic standards at farm level does not always ensure that animal health and welfare reach the high ideals of the organic principles, 3) To overcome these deficiencies, organic farmers and farmer organisations need to take ownership of organic values and, 4) In all participating countries, a strong need for training of farmers and in particular veterinarians in animal health promotion and organic principles was identified. The article presents a summary of papers presented at the five SAFO workshops.
\end{abstract}

Keywords: Organic livestock farming, diversity, animal health and welfare, veterinary.

\section{INTRODUCTION}

Livestock farming is an important part of organic farming systems, both as a part of the concept and in practice, where there is great weight on forming an integrated system with harmony between the land, the animals, and the people, involving local re-circulation of waste, feed and manure. In organic farming systems, certain values and ideas form the framework for all production. Key values are health, ecological balance or harmony at all levels of the production, local circulation of resources and the principle of precaution, fairness and care as well as sustainability and naturalness [13]. Good animal health and welfare is an important goal for organic husbandry, since animals are not just parts of the farming system: they are also sentient creatures and as such they should be given special moral considerations.

These goals and principles of high animal health and welfare as well as ensuring healthy and safe animal products of high quality present a challenge for organic livestock farming. Farmers have to develop a farming system, where animals are allowed to live in harmony with the surroundings and to experience a good quality of life, e.g. to allow the herd to perform natural behaviour, emphasising the harmony

*Address correspondence to this author at the Department of Animal Health, Welfare and Nutrition, Faculty of Agricultural Sciences; University of Aarhus, P.O.Box 50, DK- 8830 Tjele, Denmark; Tel: +45 899913 44; Fax: +458999 15 00; E-mail: Mette.Vaarst@agrsci.dk of the group and the freedom of the animals to make as many choices as possible. Farmers in such systems have to take responsibility to intervene when necessary and at first signs of disharmony in any aspect of the herd. Another major challenge is to avoid risks when producing food from animals, because of the outdoor access and the group rearing which could lead to greater exposure to environmental contaminants and present a risk to biosecurity. One potential conflict can be the presence of zoonotic organisms, such as Salmonella, Campylobacter and Escherichia coli, because organic herds have outdoor access and rely on animal manure as fertilisers and therefore can be more at risk of contamination by such bacteria than conventional herds. These identified challenges formed the background for an EU-funded concerted action project 'Sustaining animal health and food safety in organic livestock production' (SAFO), which ran between 2003-2006 with the overall aim to sustain animal health and food safety in organic livestock production systems in existing and candidate member countries of the European Union. This article focuses on the conclusions from the workshop presentations and discussions regarding organic animal production, health and welfare.

\section{MATERIAL AND METHODS}

\section{Working and Networking Methods in the SAFO Project}

A web-site is the focus for presentation and exchange of knowledge, results and products of the project 
(www.safonetwork.org), where reports and proceedings of the project are now available.

Four thematic workshops and one workshop focusing on conclusions and future perspectives were held during the three-year project (themes as indicated in the titles of the proceedings from each of the workshops; see reference list). Each workshop consisted of invited and offered presentations, followed by working group sessions to discuss the results and come to joint conclusions.

Proceedings were produced with a total of 81 oral and 39 poster presentation papers and working group reports from the workshops [4-8]. This article is based on conclusions from numerous papers including discussion reports from these proceedings, as well as related papers.

Three participant consultations were carried through. The second of these focused on implementation of the EU regulations in the EU countries, including questionnaires which involved inspection bodies and organic advisors as well as the participating researchers.

\section{RESULTS AND DISCUSSION}

\section{Highly Diverse Organic Livestock Production Systems Throughout EU}

Europe forms a highly diverse picture with regard to organic livestock farming in terms of different living conditions, for example in geographical circumstances (mountain areas or coast-lines), and different climatic situations (the differences between winter and summer). Particularly in large parts of the north-west Europe, the challenge for organic livestock production lies in a high degree of specialisation and large flock and herd sizes. In the new and preaccession member states, big challenges exist in terms of the lack of a home market for organic livestock products, limited access to organic feed stuffs and traditional farming systems, for example where tied housing is widely used. The extent to which existing organic livestock standards can guarantee the aims of organic livestock farming under all these different circumstances is one important and relevant discussion for the future development of organic livestock production as well as the EU regulation. In many EU pre-accession and new member countries, organic livestock production has been introduced within the last decade, where others have tried to establish an organic sector for 10-15 years, like Estonia, Poland or Czech Republic [9]. The importance of viewing farms as whole systems, where not only animal welfare but also environmental care should be considered, was particularly underlined in relation to organic pig production, where harmony between stocking density and land area seems to be a major challenge. More authors emphasised that sustainability in organic livestock production demands handling the complex area of resource management, soil degradation and environmental pollution.

Many development potentials of the organic sector were also pointed out, for example in Poland, where existing lowinput extensive farming systems and large grassland areas provide good opportunities for organic farming, or in Turkey, where different eco-systems and rich bio-diversity are present. The pre-condition for developing this potential is that some of the severe obstacles are removed e.g. through government or EU support. Organic livestock farming also has a potential in many European regions as a way of developing rural and / or marginal areas or areas with a tradition of extensive production like Andalusia in Spain. The transition period may be challenging, and the lack of scientific information from research in organic livestock production in some areas like e.g. Greece furthermore makes it difficult to establish organic farming traditions. One major potential in Mediterranean and mountain areas is the small ruminant. Disease challenges such as perinatal mortality exist, but many challenges seem linked to farm system development, e.g. the need to prevent nutritional deficiencies wher $100 \%$ homegrown feed is used, grazing management and general farmer management practices. Case studies in Hungary on organic goat, sheep and deer farmers showed that in the case of organic lamb production, for example, production is very difficult due to a lack of premium prices but could be developed in combination with eco-tourism or through farmer cooperatives for example. In studied goat farms the importance of the personal marketing by the farmers persuaded consumers to come back every week, and this was concluded to be of major importance.

The many common challenges in these countries include lack of home market and traditions for organic production and consumption of organic food products. This presents a particular challenge to the organic livestock production in contrast to the fruit and vegetable production where an export market sometimes can be the starting point for an organic farm production also involving livestock. Many stables are old and based on tied housing, which must be changed according to the principles and regulations of organic farming. The combination of the above mentioned factors together with no premium prices for organic products, very limited access to organic feed (concentrate) and no advisors who can guide the conversion to organic farming makes the implementation of organic production difficult [9].

\section{Animal Disease, Health and Welfare Issues in European Organic Livestock Systems}

The level of disease seemed in general to vary much between regions and countries, and organic livestock cannot be claimed to be generally healthier than conventional livestock throughout Europe. The main disease issues which were highlighted in presentations as well as in a discussion report, seemed to be similar between the countries, for example metabolic problems, lameness and mastitis in dairy cows. For beef cattle, sheep and pigs, parasitism was mentioned as a main issue, and feather pecking and cannibalism were highlighted as a main challenge in poultry. Many disease problems seemed smaller in South Europe than in NorthWestern European countries. Based on an interview study of veterinarians with experience in organic livestock farming, it was suggested that the warm, dry climate might explain this. In some surveys, the health situation in organic herds was found better in organic herds. E.g. in Austria, the dairy herds was perceived by organic dairy farmers as much improved after conversion to organic production, and in Poland a survey of 61 organic farms and 53 conventional showed that the milk quality and state of the animals appeared better in the organic herds than in the conventional. In some cases, it could be explained by quite obvious factors, such as hyperketonemia, which varied between herds but was generally lower in loose housing systems. This was suggested to illus- 
trate that the framework of organic livestock farming such as loose housing may promote health. In other surveys, no difference was found, e.g. in a survey in Slovakia, hygiene level was found equally on a very high level in both conventional, in-conversion and organic herds.

\section{Organic Poultry Presents Major Animal Health, Welfare and Production Challenges}

It was repeatedly concluded during SAFO Workshops that organic poultry production was probably the most challenging type of organic livestock production system at the moment. In one working group report, a number of common challenges and possible solutions to these throughout Europe were identified, mostly linked to the structure of large, specialised poultry flocks, although the production of organic table birds kept on mixed enterprise farms (a case study involving 4 herds) was also proved be profitable given the right structure of the market, and not linked with major problems on the farms, although challenging.

Because of the limited availability of suitable protein sources for mono-gastric animals, the question of $100 \%$ organic rations was a particular concern. Since there are some anti-nutritional factors in lupins, peas etc., there is a limit as to how much poultry can consume of these otherwise natural sources of amino acids, and high performing layers and young turkeys are the two types most likely to be undersupplied with essential amino acids (AA). Possible solutions could be slower growing strains of birds, optimising the use of home-grown pulses, and innovative nutritional strategies such as lowering the energy density of the diet relative to AA content.

Some studies showed that the level of mortality in freerange and organic poultry was higher than in conventional herds, and mainly caused by feather pecking and endoparasites. These are multifactorial conditions and among the causes, it was suggested that a deficient immune response could derive an artificial bird management in young chicken, keeping them indoor and with no contact between chicken and mother. The benefit of outdoor runs for both chicken and egg-layers in order to avoid feather pecking was emphasised in more studies. One way of solving this could be treatment with intestinal flora on the first day of life, and rearing young chickens with healthy older hens in free-range conditions. With regard to encouraging the hens to use the outdoor run, this can be solved by housing the poultry in smaller flocks as well as scattering grain away from the house and providing shelters. In conclusion, some major challenges in the organic poultry production can be managed by introducing less intensive methods which are also better in accordance with the organic principles.

\section{The Management Practices Crucial for the Animal Health and Welfare Situation}

In general, a wealth of information exists about disease prevention in organic farms or relevant to organic farming systems. Schumacher (2004) [10] represented the perspectives of a German farmer and the German organic organisation Bioland and claimed that $90 \%$ of problems in organic livestock farms are management problems rather than technical issues requiring further research. Löser (2004) [11] supported this within the context of organic pig production in Germany: the stockpersons are often found to be inadequately educated, which has a severe negative impact on birth assistance, disease occurrence and poor hygiene. This was supported in working groups and by other presenters. In sheep production, one working group concluded that the management skills of farmers, labour supply and quality and provision of advice were seen as main key issues in relation to animal health and welfare. In organic pig production the many challenges seemed to illustrate the conflict between the price and the production costs in combination with the management routines required to make a good organic product, and therefore significant improvements could be made with regard to management of organic pigs. In conclusion, the implementation of the standards alone cannot be said to guarantee the high animal health and welfare level which is an explicit goal for organic livestock production. This forms background for recommending that animal health and welfare planning should be a part of organic livestock production both in relation to conversion and after conversion.

\section{Grassland Management in Organic Farming}

Grassland management is an obvious basis for and a major issue of relevance for organic livestock production. In some settings, the composition and content of grassland areas was found better in organic farms than in conventional farms, which form a good basis of an organic farming system in terms of summer grazing and hay making for the winter. SAFO participants generally experienced many challenges related to climate, soil quality, traditions (such as communal grazing and trans-humance) and integration of livestock production into whole farming systems. In many herds, no health problems seemed related to pasture-based animals, and performance characteristics as well as carcass quality were generally better than in permanently housed animals, and carcass quality was better in these animals.

One important aspect of grassland management is the handling of endoparasites, although a questionnaire survey e.g. has shown that organic farmers gave higher priority to grass production than parasite prevention through their management strategies. The composition of diet and pasture can have potentially great importance for the parasite burden in the animals, and alternate or mixed grazing of older and younger cattle has also been concluded to lead to a substantial reduction in faecal egg count. A major EU-funded project WORMCOPS (http://www.wormcops.org) focusing on bioactive forages (e.g. Lotus and chicory containing secondary metabolites such as tannins), which have been shown to reduce the worm infestation in small ruminants, was presented and discussed several times during the SAFO project. In Greece, feeding of lambs with clinoptilolite (a natural zeolite) had a potential positive effect on carcass conformation and worm burden. Some of the methods such as nematophagous fungi seemed promising but more specific guidelines for their use at farm level are needed. More research is needed to advise on how to use these alternative methods at the farm level.

\section{Biosecurity and Zoonotic Disease in Organic Livestock Farming}

Biosecurity was defined as 'the sum of the management measures to reduce the risk of introducing new disease agents to the farm', and is an important issue for organic 
farms, particularly in areas with high level of disease challenges. In a work group report it was emphasised that formal health planning was seen as the main means of implementing improved biosecurity at the farm level. Although organic farming provides better conditions for residue-free animal products and animal welfare in terms of natural behaviour and outdoor access, it contains a potentially higher risk of infectious and parasitic diseases, compared with conventional and in particularly indoor livestock systems, through group housing, outdoor access and the use of straw and litter. One example is Toxoplasma gondii, where pigs from conventional indoor-reared pigs were all toxoplasma-negative, where positive samples were found in organic and conventional free-range pigs. Salmonella infections were also shown to be transmitted from infected to non-infected pigs on pasture, although the shedding was low and intermittent. Jensen (2006) [12] furthermore concluded that the level of infection of Salmonella and Campylobacter varied widely between systems as well as individuals. No Salmonella was found in associated wildlife but it was found that Salmonella could persist in the environment over a 6 week sampling period, thus providing a reservoir for infection of new pigs introduced to the site. In poultry, campylobacter and salmonella present the major challenge, and infected animals may not always be clinically ill. In organic broiler production in the Netherlands the incidence of Salmonella was lower and Campylobacter higher in organic flocks compared to conventional flocks, maybe as a result of a higher age at slaughter, or different breeds. In Finland, where outdoor access is much restricted during winter and biosecurity has a high national priority, it was found in an on-farm study including 20 herds that Salmonella was rare and Campylobacter in organic eggs poses no public health risk, but that parasites are common. This must clearly be seen in the light of the special Finnish conditions. Paratuberculosis (Johne's disease) is a potential zoonoses, and no difference between organic and conventional farms has been found, e.g. in the Netherlands. A special conflict may exist here for the organic herd situation, aiming at 'naturalness', because Johne's disease is transferred between mother and new-born calves. Within organic dairy farming, there is a great interest in eliminating Johne's disease because, amongst other reasons, it gives the farmer an opportunity to implement alternatives to the production method, e.g. letting the newborn calf suckle its mother. For all animal species, working groups at the third SAFO workshop concerning zoonotic diseases concluded that bio-security, improved hygiene, manure handling, feeding hygiene and consumer education were solutions to most of the risks. The actual presence of these practices may also explain why the potential risks for zoonoses in connection with organic farming were not supported by practical experience with increased problems in organic animal products.

\section{Breeding for Good Animal Health and Welfare}

The emphasis on using traditional breeds was recommended to be an issue for future development of organic livestock farming in many countries. Native breeds were studied e.g. in Hungary. Arguments that there is a great potential for development of an organic breeding index were presented, where, for example, longevity, good milk yield and high protein content are prioritized. The selection of bulls with qualities relevant to organic dairy production was pointed to as important. The need for developing breeding programmes which meet this need to a greater extent than the existing breeding programmes was also emphasised. This area should also be addressed in research initiatives in the future.

\section{Disease Treatment and the Use of Veterinary Medicine in Organic Agriculture}

The EU Regulation 2092/91 requires a doubling of the withdrawal period for allopathic veterinary medicines. The question addressed in this project was primarily a food safety focus. However, the findings of antibiotic (AB) resistant bacteria on organic and conventional farms in USA, UK and Denmark was also discussed, and AB resistant bacteria were found present on organic dairy, pig and broiler farms, although lower proportions of the bacterial populations on organic farms were AB resistant. A survey of medical treatments used in organic dairy herds in the Netherlands showed that $60 \%$ of medicines used were conventional medicines, including antibiotics for treatment of clinical mastitis and foot disease (the two most common problems) and antiparasiticides for gastrointestinal and lung disease. More trials were recommended to be initiated in order to show an effect of alternative treatments, where the effect had not been properly investigated. In a work group report, it was agreed that in some specific areas there is a need to identify and handle risks concerning the use of veterinary medicine products. The impact on the environment must be determined better, and for organic farming risks should be minimised e.g. concerning the use of copper sulphate and antiparasitic agents, and resistance to some specific drugs such as the ones containing synthetic pyrethroids should be investigated. All measures taken in order to meet potential food safety risks and minimise the use of allopathic medicine, may be met by improved animal health and welfare, in order to avoid negative side effects following non-treatment-policies in organic herds.

\section{Requirement for Animal Health Planning and Including Animal Based Parameters in Herd Evaluation}

The standards for organic livestock production are based on the organic principles. It is important to distinguish between principles which are underpinned by a value system closely related to ethical ideas and what can be described as an 'organic philosophy', and the standards, which describes the practices which are used to reach these goals. The EU Regulation is under continuous discussion and current revision, aiming at a simpler, clearer and more transparent Council Regulation. One major task of the SAFO Network has been to analyse and give recommendations for further development of the EU Regulation for organic farming. Based on conclusions from papers and discussions in the SAFO network as well as participant consultation, the SAFO Organic Standards Development Working Group recommended that each organic livestock enterprise should produce an animal health plan. Conversion plans seldom cover the livestock enterprises and there is a lack of training and education of farmers in health promotion in organic herds. A health plan should be made both in relation to conversion and in general for the organic herd and farm. Since the existence of organic standards alone was concluded not to guar- 
antee that the aim at high animal welfare and health for organic farming, health and welfare outputs should be in focus when evaluating the herd. Certification bodies should therefore establish a regular monitoring system for animal health data. This should be linked with the above mentioned point about making animal based assessments.

\section{Advisory Service and the Need for Education in Organic Livestock Farming Methods}

It was a conclusion repeated in many working groups, participant consultancies and papers that organic livestock farming lacked good advisors, and in particular veterinarians, and the need for education of veterinarians in the holistic system approach of organic livestock farming, and preventive disease management was emphasised several times. In a British study, it was found that often, farmers obtained their advice mostly from their certification body, from other farmers and from homoeopathy pharmacies rather than from their veterinary practitioner, and that their veterinarians mostly had a negative attitude towards organic production. In a second study examining the attitudes of inspectors, advisers and vets to the organic livestock standards, she again found that veterinarians had the most negative attitude. In a number of countries, especially in the new EU member countries, both conventional and organic farmers have to develop an animal health plan in order to ensure safe and healthy animal products, e.g. in Slovakia and Latvia, in some cases with particular focus on potential infectious diseases such as rabies, tuberculosis and brucellosis, which still present a problem for public health and have to be addressed both in conventional and organic herds. In a work group report, it was concluded that animal health planning should deal with biosecurity, zoonotic diseases and should be farm specific and dynamic with reasonable time-limited goals. It was furthermore emphasised that the farmer's ownership over the animal health plan is very important, and that it should ideally be combined with an adequate, well-trained advisory board, although this seemed to be lacking in most of the participating countries. In some new EU membership countries, e.g. Poland, the implementation of organic farming is followed by research, teaching material and education programmes, where a total number of 156 advisors (not including veterinarians) are involved in the development of organic farming. At the same time, it was concluded that involvement of advisors and veterinarians should be based on their interest, knowledge and skills in organic livestock farming.

\section{CONCLUSIONS}

The diversity between livestock farming systems in different European regions was clearly demonstrated in all activities and discussions within the SAFO network. This limits the possibilities for technology transfer between regions and presents a clear challenge to the harmonisation of the EU Regulation.

Much knowledge about animal health and welfare exists, but is not implemented and needs to be exchanged - in some cases translated between languages - and adjusted to local conditions.

The existence of Standards alone does not ensure a high level of animal health and welfare in organic livestock sys- tems. Research found similar but not necessarily better animal health and welfare in organic compared with conventional livestock systems. The difference between farms seems generally bigger than a systematic difference between organic and conventional herds, due to the farm management factor. This supports the recommendation that animal health and welfare planning should be a part of organic livestock farming both in relation to conversion and after conversion in order to ensure a continuous active health promoting effort. Furthermore, it was suggested that animal based parameters should be included as part of the certification process of organic livestock farms in order to ensure that the organic production system also had a visible positive effect on the animals.

Breeding and ensuring that farmers can identify and obtain breeds suitable for organic production are suggested as an important future focus area for organic production and research.

The majority of Network participants experienced a severe lack of good veterinary and animal health advisors who were familiar with organic principles and practices. Education of advisors as well as of farmers and consumers is emphasised as an important future challenge area.

A potential risk for zoonoses (infectious diseases transferred between animals and humans) exists in organic farming primarily because of the outdoor access which all organic animals are entitled to, but few studies report actual problems. Factors such as sufficient space and feed plus good biosecurity on the farms indicate that management is important in reducing this risk, but further research is needed in this area to understand the risk. The potential risk further supports the recommendation of implementing herd specific animal health and welfare planning processes.

\section{ACKNOWLEDGEMENTS}

The success of the SAFO network has been a result of the active participation and numerous contributions of many people, who have participated in the workshops, roadshows and / or debate on the internet. We gratefully acknowledge and thank all of you, who took part in this. The whole network was possible due to the funds from the EU Commission, as a concerted action project under Framework 5, QLK5-CT-2002-02541.

\section{REFERENCES}

[1] Alrøe HF, Vaarst M, Kristensen ES. Does organic farming face distinctive livestock welfare issues? A conceptual analysis. J Agric Environ Ethics 2001; 14(3): 275-99.

[2] Alrøe HF, Kristensen ES. Toward a systemic ethic: In search of an ethical basis for sustainability and precaution. Environ Ethics 2003; 25(1): 59-78

[3] IFOAM. The principles of Organic Agriculture. 2007. http://www ifoam.org/about_ifoam/principles/index.html

[4] Hovi M, Martini A, Padel S, Eds. Socio-economic aspects of animal health and food safety in organic farming systems. Proceedings of the $1^{\text {st }}$ SAFO Workshop 5-7 Sep. 2003, Florence, Italy. Available at www.safonetwork.org

[5] Hovi M, Sundrum A, Padel S, Eds. Organic livestock farming: potential and limitations of husbandry practice to secure animal health and welfare and food quality. Proceedings of the $2^{\text {nd }}$ SAFO Workshop 25-27 March 2004(a), Witzenhausen, Germany. Available at www.safonetwork.org

[6] Hovi M, Zastawny J, Padel S, Eds. Enhancing animal health security and food safety in organic livestock production. Proceedings of 
the $3^{\text {rd }}$ SAFO Workshop 16-18 Sep. 2004(b), Falenty, Poland, 1520. Available at www.safonetwork.org

[7] Hovi M, Walkenhorst M, Padel S, Eds. Systems development: quality and safety of organic livestock products. Proceedings of the $4^{\text {th }}$ SAFO Workshop 17-19 March 2005, Frick, Switzerland, 7-16. Available at www.safonetwork.org

[8] Rymer C, Vaarst M, Padel S. Future perspectives for animal health on organic farms: main findings, conslusions and receommendations from SAFO Network. Proceedings of the $5^{\text {th }}$ SAFO Workshop 1 June 2006, Odense, Denmark, 7-42. Available at www.safonet work.org

[9] Younie D, Vaarst M, Leming R. Challenges identified in relation to the implementation of EU Regulation 2092/91 and principles for organic livestock production in new EU member states. Biological Agriculture and Horticulture 2008 (accepted).
[10] Schumacher U. Animal welfare and health problem areas from an organic farmer's point of view. In: Hovi M, Sundrum A, Padel S, Eds. Organic livestock farming: potential and limitations of husbandry practice to secure animal health and welfare and food quality. Proceedings of the $2^{\text {nd }}$ SAFO Workshop 25-27 March 2004, Witzenhausen, Germany, 25-26.

[11] Löser R. Organic pig husbandry in Germany: structure, economics and market. In: Hovi M, Zastawny J, Padel S, Eds. Enhancing animal health security and food safety in organic livestock production. Proceedings of the $3^{\text {rd }}$ SAFO Workshop 16-18 Sep. 2004, Falenty, Poland, 167-170.

[12] Jensen A. Bacterial infection risk associated with outdoor organic pig production with special reference to Salmonella and Campylobacter infection. Ph.D. thesis, 2006. The Royal Veterinary and Agricultural University, Denmark.

(C) Vaarst et al.; Licensee Bentham Open.

This is an open access article licensed under the terms of the Creative Commons Attribution Non-Commercial License (http://creativecommons.org/licenses/by$\mathrm{nc} / 3.0 /$ ) which permits unrestricted, non-commercial use, distribution and reproduction in any medium, provided the work is properly cited. 